\title{
Information Sharing among the Government, University, and Industry: A CIS Approach
}

\author{
Muhammad Rabiul Hasan and Abdul Rahman Ahmad Dahlan \\ Department of Information systems, Faculty of Information and Communication Technology, \\ International Islamic University Malaysia, Kuala Lumpur, Malaysia
}

Correspondence should be addressed to: Muhammad Rabiul Hasan; rabiul.iiu@gmail.com

Received 27 June 2012; Accepted 18 November 2012; Published 24 July 2013

Academic Editor: Zuzana Tučková

Copyright (C 2013 Muhammad Rabiul Hasan and Abdul Rahman Ahmad Dahlan. Distributed under Creative Commons CC-BY 3.0

\begin{abstract}
The study explores the concept of collaborative information system through the combined deployment of Quadruple Helix Model (QHM) collaboration promoted by Agensi Inovasi Malaysia, an agency under the Ministry of Science, Technology and Innovation Malaysia (MOSTI) and the "Whole-of-Government" (WoG) concept of ICT implementation across the Malaysian government agencies promoted by MAMPU. The four QHM collaborators are the government, universities, industries and citizens, which are involved in the human capital development and workforce employment in any country. The idea of having collaboration among all these four collaborators in information system is vital, where in the Innovation Economy, knowledge and information no longer resides just within the walls of an organization. QHM's premise is that all four actors have equal roles to play in stimulating innovative human capital development in a country. The prime objective of this study is to investigate the possibility of four QHM actors collaborating by leveraging a standard online platform where each of them is able to access, exchange, and represent information for the greater benefit of the citizens for a particular country, especially in the context of Malaysia. The description of the collaborators includes the functionalities and information services offered by each of the collaborative icon together with brief concept of implementation mechanism. As the expected outcome, the citizens would get ample information based on their needs. The discussion incorporates the justification of why four actors have been chosen for collaboration in this study. Finally, future implications indicate the direction of the design and successful implementation of this study.
\end{abstract}

Keywords: Collaborative information system; CIS; Information sharing; Collaborative web portal; Malaysia.

\section{Introduction}

The advancement of the Information and Communication Technology (ICT) and World Wide Web (WWW) has significant impact on the process of information sharing. Though the demand for information delivery mechanism is not new, but for collaborative information system or mechanism is the demand for today. Collaboration can be implemented in many ways depending on the needs. Current research on innovation emphasizes the significance of collaboration by means

Cite this Article as: Muhammad Rabiul Hasan and Abdul Rahman Ahmad Dahlan (2013), "Information Sharing among the Government, University, and Industry: A CIS Approach," Communications of the IBIMA, Vol. 2013 (2013), Article ID 322363, DOI: 10.5171/2013.322363 
of inter-organizational networks (Bothos et al, 2008). Based on the existing literature, it is found that earlier researches conducted by Getz, (1977), Swanson \& Culnan (1978) and Molhort (1985) had predicted the combination of data resources into a single entity. This was due to the realization that information system often requires the presence of data from external environment so as to increase its efficiency.

Even though the Internet and the web have brought much flexibility, but still many challenges remain around due to the endless demands from the users. In general, for most of the cases, information is available on the web and the information resources are located in isolation. Therefore, users often face challenges to find intended information in a short time with less effort. At this background, the necessity of having a collaborative information sharing system has been risen, where users can engage in shared activity, usually from remote locations, work together toward a common goal, and have a vital need to share information and exchange requests with each other (Farley, J., 1998).

Looking at the past, over the years there has been an increase in partnerships between government's data repository with various public and the private domains. Therefore, this study came up with a proposal which expects to collaborate with the government, university, and industry in order to serve the potential graduates, parents, as well as citizens with a wider information pool at a single portal. In brief, the proposed collaborative information sharing system would be used to present information from diverse sources e.g. Malaysian egovernment web portal, SME corporation web portal, and Malaysian Qualifications Agency (MQA) portal in a unified way. In this paper, the definition of collaborative information system together with short literature review has been presented, and in addition, a brief concept and functionalities of each entity in the study model has been incorporated.

\section{Problem Statement}

This study was undertaken to explore the idea of collaboration and information sharing amongst the four QHM actors/collaborators, namely the Government, Industry, Academia and Citizen which are involved in human capital development (MOSTI, 2011) and workforce employment in any country. And within the Government, the "Whole-of-Government" (WoG) concept of ICT implementation across the Malaysian government agencies promoted by MAMPU (MAMPU, 2011) is also been incorporated. The concept of QHM/"WoG" collaboration and information sharing by building and leveraging on a single information sharing system was rated to be crucial; because in isolation those four QHM actors cannot produce the necessary human capital in meeting the nation's aspiration to become a highincome; knowledge intensive and innovation-led economy.

\section{Objectives of the Study}

The main objectives of this study are as follows:

- To examine the possibility of QHM/"WoG" collaboration and information sharing with the Government, University, Industry and Citizen by having a standard online platform where each of them are able to access, exchange, and represent information for the greater benefits of the citizens in a particular country, especially in the context of Malaysia.

- To present information from diverse sources e.g. Malaysian e-government web portal, SME corporation web portal, and Malaysian Qualifications Agency (MQA) portal in a unified way in an effort aimed at bringing together the industry, academics, practitioners and government to share knowledge, promote new thinking, help in the design of new curricula, shape public policy and inform the public. 
- To support citizens with the necessary information that they demand from the industry and academia perspectives.

- To create social and economical values for the citizens through developing a collaborative information system that is available all the time.

\section{Significance of the Study}

By providing this central pool for all the required information to the various stakeholders, this system will help the various decision makers to reach informed decisions.

\section{The Government Perspectives:}

For example the government will find it easier to plan for its current and future graduates by creating the necessary job opportunities based on its expected graduates as it also advises its institutions of higher learning as to which area they should pay special attention. Through this portal, the government will know how many jobs to create per each category or advise universities to train more students in a particular area where it expects to create jobs in a given timeframe and less number of student in other fields which don't seem to have any job opportunities in that particular time frame.

\section{Industry Perspectives:}

The system is expected to benefit the industry in a way of aiding them in getting potential employees according to their needs; actually they would find right candidates for the right positions, and employers will not need to spend lot of money in providing basic skills-training.

\section{Higher Learning Institution Perspectives:}

The MQA portal will be able to pull information from the proposed collaborative system about; the available and planned jobs at industry and government, the required skills for each job category, details about available scholarships, details about available corporate institutions and information about the research grants.

\section{General Public Perspectives:}

Finally, the general public including parents, guardians and students will be able to get free carrier guidance information. This will include information about; the available and planed jobs and remuneration attached to each job category, the required skills, universities that offer the relevant courses etc. This will help students choose the right courses based on their preference and also based on the knowledge of the availability of jobs and the remunerations attached to each particular professional category. The proposed collaborative system will employ a strong algorithm that will be able to relate the job to the skills required, then to the relevant courses that should be studies, and finally point at the universities that offer those courses. Through this collaborative system the public will be able to give a feedback to all stakeholders especially the government about the details of unemployed and underemployed graduates, and any other complaints and suggestions.

\section{Understanding Information Systems (CIS) \\ Collaborative}

To understand collaborative information systems, first we need to know what collaboration is. The concept of collaboration is a vast which can be applied to numerous situations (Bénaben et al, n.d.).

It is known as a recursive process where two or more persons or organizations work together to understand shared goals (wiki). For example, an intellectual effort which is creative in nature made by sharing knowledge, learning and building consensus. 
Collaboration in the field of business could be found in both inter and intraorganization. In the education sector, collaborative partnerships are developed by mutual agreement between two or more partners to work together on projects and activities which will enhance the quality of education for students while improving critical skills to success at the workplace. CIS requires having an intermediate entity available in the middle of the network which should manage all the specifications of each partner or entity of the collaborative partners (Bénaben et al, n.d.).

Overall, collaborative information systems is the information sharing among the parties through a particular system platform that houses dynamic and interactive information seeking and receiving by the user groups. Collaborative information systems integrate and coordinate information from diverse sources (El-Bibany et al, 1991). For this proposed project, collaborative information systems (CIS) means a sharing of information and representation of all information come from associated parties (industries, government, citizens and higher learning institutions) via a dynamic web portal as an interactive platform to its users.

\section{Literature Review}

The term "Collaboration" is not an option, but a necessity, and thus, is often required or encouraged for activities that are so complex or difficult to deal for an individual, people or organization (Denning, P. J. and Yaholkovsky, P., 2008). In some circumstances involving information seeking and information sharing also called as collaborative effort. Collaborative Information Systems allow users to share information through an emerging collection of tools and platforms where people are able to connect and collaborate (Javanmardi, and Lopes, 2007).

According to Twidale and Nichols (1996) they have argued that introducing support for collaborative work into information retrieval system would help end-users to learn and use the system more effectively.
There was a study conducted by Morris (2008) that showed, from 204 knowledge workers that the majority of them wanted to collaborate to every specific goal. Shah (2008) argued that our understanding of how people work in collaboration of information sharing projects, and the tools that support such activities are inadequate. Comparing to the traditional information system which creates huge attention to the single enterprise or entity and it is unable to collaborate significantly. However, collaborative information system is different from that and it develops an information network to link the isolated information point from each entity (Xiu, 2010).

From the view of existing literatures of collaborative information systems (CIS), it is obvious that though much research have been conducted in the field of CIS, however, for information sharing among the public and private sectors though gateway portal is very limited. Yet, no much research found available which represents the idea or implementation of CIS among the government, industries, and higher learning institutions. Though Sohn et al (2007) talked about designing and implementing Information System for the MBO of National Research and Development Projects incorporated by Industries, Universities and Governmentsupported Research Institutions, but how to achieve successful implementation of that project is still lacking.

However, an effort has been established in Malaysia to collaborate innovation which is named as "Innovation Xchange: connecting for collaborative innovation". Its main services are for the organizations rather than individual people or general public. There is no offering as collaborative information system at Innovation Xchange (Innovation Xchange, 2011). No information available on the Institutions of Higher Learning (IHL) or Industry or Government in order to serve citizens' needs. It has a section to ask questions about industry, academia, and government; but no available information on university curricula, potential graduates, and industry demand in terms of employee skills. 
Overall, Innovation Xchange is a profit oriented organization and does not serve the purpose of the proposed "collaborative information system: connecting the government, university and industry".

\section{Description of the Proposed System}

The proposed collaborative information portal inherits the main purpose of the Multimedia Super Corridor (MSC) Malaysia i.e. boosting Malaysia into an information and knowledge age with the extension of the scope of the parties or systems that will be collaborated. The portal will feature on education, government and industrial sector. The portal shall be working by pulling information from the three knowledge repository to a single platform. These knowledge repositories will include Malaysian e-government portal, industry portal represented by SME-corporation, and higher learning institution portal represented by coordination of Malaysian Qualifications Agency (MQA).

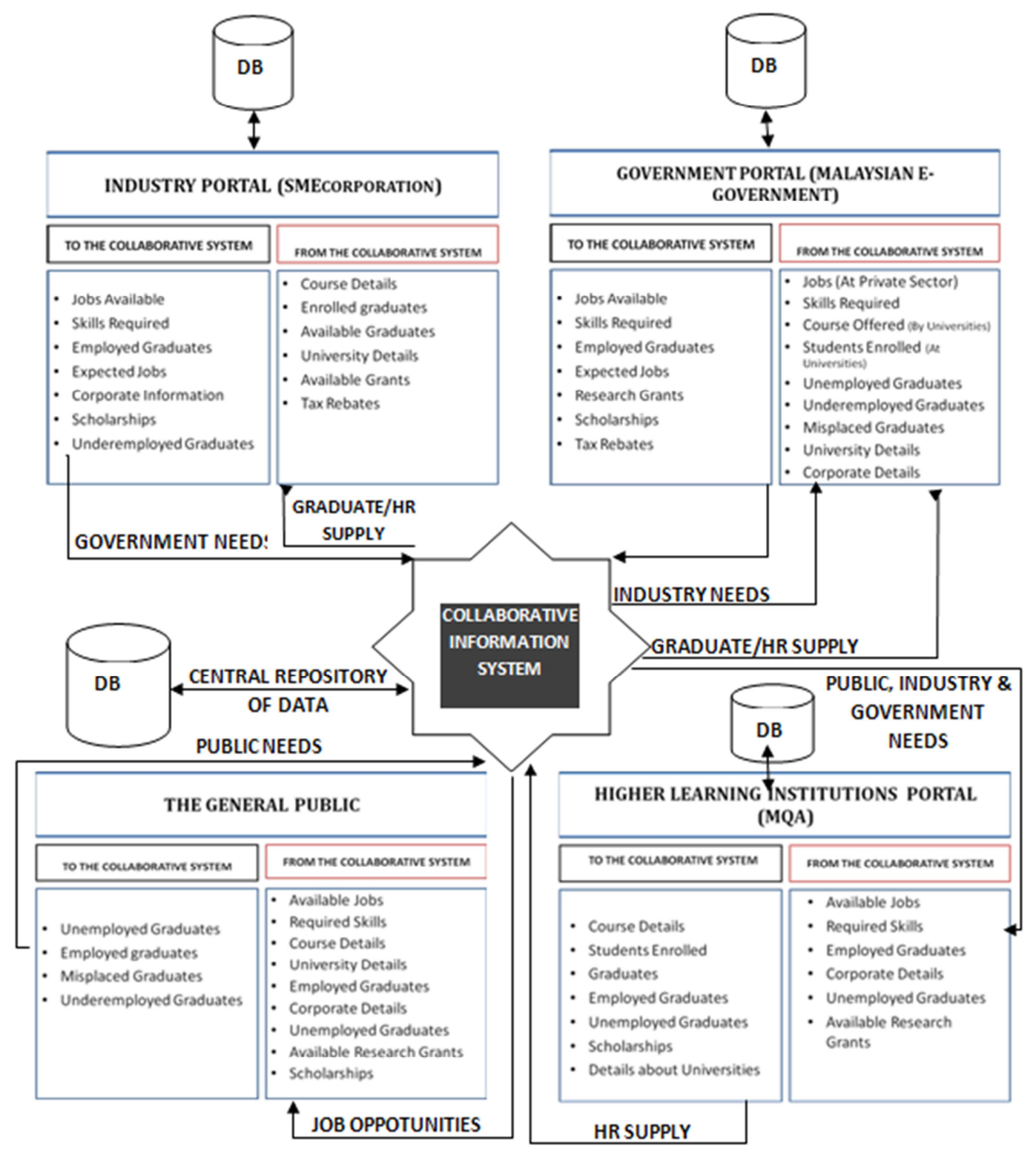

Figure1: Proposed Model for the Collaborative Information System (El-Bibany et al, 1991 and Bénaben et al, n.d.) 
By providing this central pool for all the required information to the various stakeholders, this system will help various decision makers to reach informed decisions. For example, the government will find it easier to plan for its current and future graduates by creating the necessary job opportunities based on its expected graduates. Government would also advise its institutions of higher learning as to which area they should pay special attention. Through this portal, the government will know how many jobs to create for each category, or advise universities to train more students in a particular area where it expects to create jobs in a given timeframe, and less number of student in other fields which don't seem to have any job opportunities in that particular time frame.

\section{Malaysian E-Government Portal}

In an effort aimed at offering a single source of information to its citizens, the government of Malaysia in 1997 developed an "e-government portal" (Kaur, 2006). This initiative was aimed at increasing the speed and quality of service delivery towards its citizens (Malaysia Government's official portal, 2011). This portal has been able to improve the convenience, accessibility and efficiency of communication within the society and businesses. As a result, this portal has improved information flow and processes within the government, thus increasing the efficiency and effectiveness of policy development and enforcement. However, this portal is still missing out some important information yet this same information is kept in isolation on some other independent portals like the MQA and SME portals among others.

This proposed collaborative information system will help in bridging this gap by providing a mechanism to connect these independent portals together thereby eliminating redundancies and inconsistencies. Through this collaborative information system the government will be able to provide information regarding government job opportunities together with the relevant academic requirements.
The other services will include providing information regarding availability of education and research grants and investment opportunities. On the other hand the government will be able to get information pertaining to the currently enrolled students in all universities and colleges around the country. The government will also be able to get a detailed list of available jobs in the private sector, lists of courses offered by each university or college, minimum academic requirements for each job category and information regarding the unemployed graduates, plus any other relevant information.

With this proposed collaborative information system, the Government portal has the potential to: (a) enhance government service delivery through the streamlining of government ICT architecture; (b) optimize and enhance ICT operations through government, industry and academia ICT infrastructure consolidation - wide area network, databases, applications and servers farms; and (c) intensify inter-organizational and inter-agency collaboration towards fostering "whole-of-government" public services in developing the necessary graduates and workforce to meet the nation's strategy to become a high-income, knowledge intensive and innovation-led economy.

\section{Higher Learning Institution Portal}

The Malaysian Qualification Agency (MQA) was set up to improve the quality of academic programs in institutions of higher learning. Through this agency the government evaluates the quality of services and programs in these institutions. The Malaysian Qualification Agency conducts its main activities through its portal known as the MQA portal (Malaysian Qualification Agency, 2011). In view of the proposed collaborative web portal, the MQA is expected to supply information regarding the curriculum used by the higher education and the number of students in each educational term. Other information will include details about available scholarships, universities and 
graduates. In return the MQA portal will be able to pull information from the proposed collaborative system about the available and planned jobs at industry and government, the required skills for each job category and research grants among other issues.

\section{Industry Representative Portal}

There are three relative portals to represent the industries in Malaysia which are found in this study such as the portal of the ministry of international trade and industry, SMEinfo portal, and SMEcorp portal. As SME annual report 2009/10 identifies the total number of industries established based on different sectors (SME Annual report (2009/10): Transforming to the New Economic Model, 2011), it is then necessary to analyze and understand which portal will best serve the purpose of this project. The following is the short descriptions of functionalities of three selected alternative portals in order to justify how SMEcorp will be able to represent the majority of industries in Malaysia compared to the other two alternatives.

\section{What Does the Portal of the Ministry of International Trade and Industry Have?}

There is a portal managed by the Ministry of International Trade and Industry Malaysia which provides many supports and resources for the SMEs in Malaysia, but there is no information on the SMEs themselves such as what type of activities a SME performs, what are their products, what are their milestones and strategic goals etc., are absent in the portal concerning a particular SME. No dynamic communication is established among the SME owners and the ministry side through the portal. If one browses through the portal and intend to know about the industry information, he or she would find industry profiles where types of industry are manufacturing and services which do not provide the details of each industry except providing the information on requirements, scopes, status and investments of certain type of industry. Overall, the portal of the Ministry of
International Trade and Industry Malaysia does not serve the purpose what this paper trying to focus (SME in Malaysia, 2011).

\section{What Does SMEinfo Portal Have?}

The SMEinfo is known as "One Stop Information portal" for Small and Medium Enterprises (SMEs), which provides information on all aspects of SME Development including some areas such as Financing, Advisory Services, Training Programs, Business and Networking opportunities as well as other SMEs Developmental Programs or initiatives by the Malaysian Government and the Private Sectors. In the portal, there is a section called "SME Business Directory" and in that directory there are seven business sectors having total 16920 registered companies as estimated on January 26, 2011 (SME Business Directory, 2011). Each registered company has its own profile.

\section{What Does SMECorporation Portal Have?}

The portal of SME-corporation promotes the development of competitive and innovative SMEs through effective supervision and provision of business support. It provides business advisory services through the "SME Business Centre" and disseminates information regarding Government funds and inducement on SMEs. It also improvises national SME database, facilitates linkages with large companies and multinational corporations, and being channel for feedback on various SME issues. SMEcorporation portal has a section called "List of Companies" where 29 categories of companies are listed there (SME Corporation Malaysia: List of companies, 2011). The difference between SMEinfo and SMEcorp (in term of the intention of this study) is that SMEcorp has many categories of industry compared to SMEinfo. Thus, for this study, SMEcorp has been chosen to represent the model of industry portal, and expected to share information to, and from the proposed collaborative web portal. 


\section{What to Share by SMEcorp to Collaborative Web Portal and vice Versa?}

From the perspective of industry portal, the employers would provide feedbacks on the required skills of the potential workforces, the available vacancies in the respective companies, currently employed entry level graduates, and corporate information. On the other hand, they would receive the information on the potential supply of workforce for the industries, information on various courses that graduates have gone through, and currently enrolled students etc. Expected benefits of the system would be that the employers receive graduates or job seekers according to their needs. Actually, they would find right candidates for the right positions, and employers will not need to spend lot of money for providing basic skill-training as universities expected to input the basic ground into the graduates which is desired by the employers.

\section{General Public Perspective}

Finally, the general public including parents, guardians and students will be able to get free carrier guidance information. This will include information about; the available and planed jobs and remuneration attached to each job category, the required skills, universities that offer the relevant courses etc. This will help students choose the right courses based on their preference and also based on the knowledge of the availability of jobs and the remunerations attached to each particular professional category. The proposed collaborative system will employ a strong algorithm that will be able to relate the job to the skills required, then to the relevant courses that should be studies and finally point at the universities that offer those courses. Through this collaborative system the public will be able to give a feedback to all stakeholders especially the government about the details of unemployed and underemployed graduates, and any other complaints and suggestions.

\section{Discussion on the Study Model}

In the study model, we have a representative for each collaborative partner (government, university, industry). In that case, government portal is represented by Malaysian e-Government portal, industry portal is represented by SME Corporation, and higher-learning institution portal is represented by Malaysian Qualification Agency (MQA). The reason of selecting a representative for each participative partner is that currently there is no specific portal for any of those three. Therefore, for this study we have gone through many alternatives and justified what are the existing portals that serve the purposes of collaborative information sharing system. Though, there is a portal representing almost all higher learning institutions in Malaysia (Malaysia University Portal, 2011) but that is serving different means than the objectives of proposed collaborative web portal.

\section{Use Case Diagram for the System}

Use case diagram in figure- 2 shows the interactions and functions to be involved in the system with the active participation by all the potential actors. The description of the Use Case diagram is presented in the following table (table-1) with use case summary. 


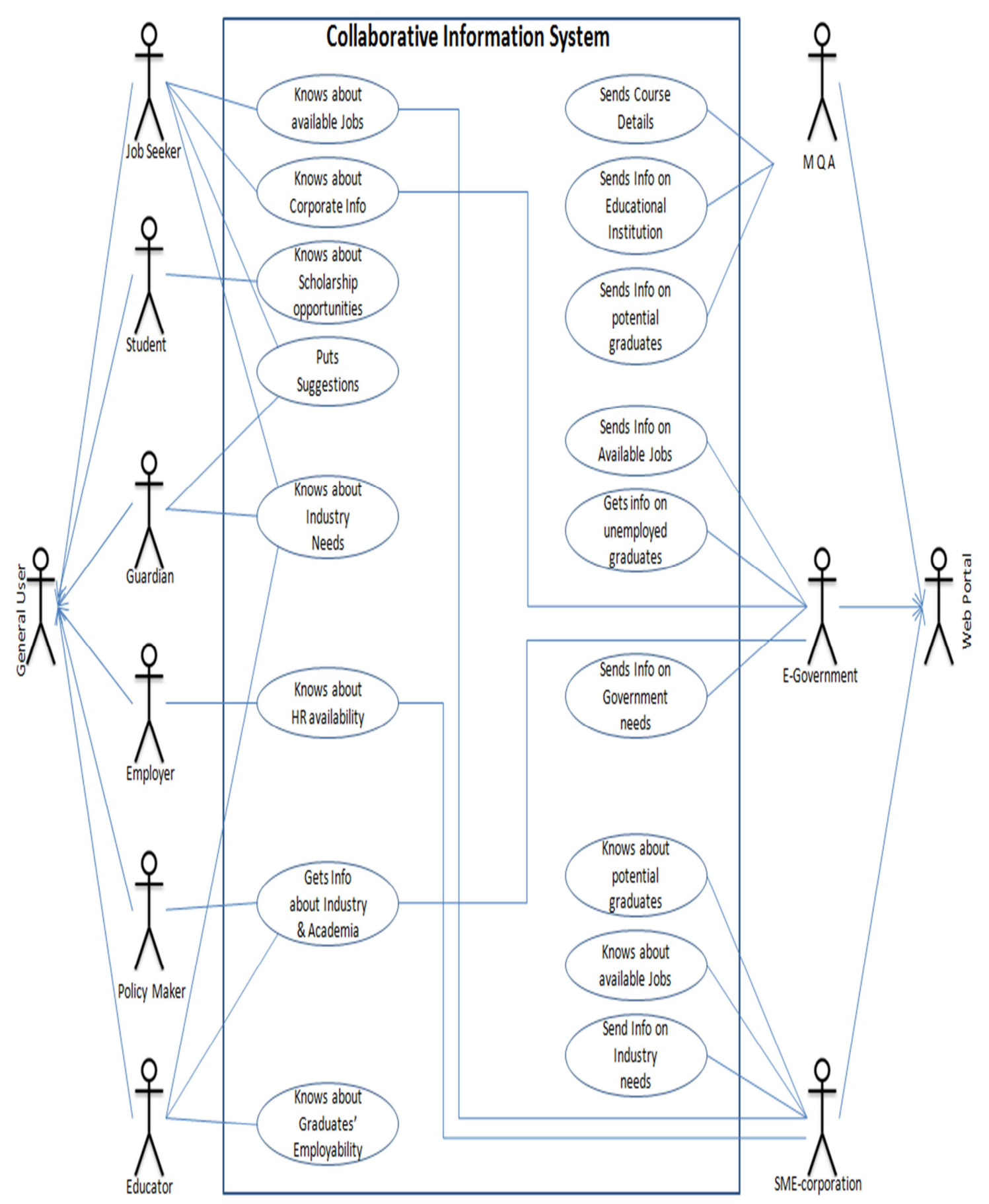

Figure-2: Use Case Diagram 


\section{Use Case Summary for the Proposed System}

Table-1: Use Case Summary for the Proposed System

\begin{tabular}{|c|c|c|}
\hline Name & Description & Actors \\
\hline Jobseeker & $\begin{array}{l}\text { Jobseeker can receive available information on jobs at the } \\
\text { collaborative portal, and the portal administrator can supply } \\
\text { those information though the portal's database. As the } \\
\text { jobseekers search for various information on jobs; therefore, } \\
\text { the portal administrator checks or observes the query from } \\
\text { the jobseekers to further add, enhance and update the } \\
\text { offerings available for them at the collaborative information } \\
\text { system portal. }\end{array}$ & $\begin{array}{l}\text { Collaborative } \\
\text { System } \\
\text { Administrator }\end{array}$ \\
\hline Student & $\begin{array}{l}\text { Students can receive available information on the academia } \\
\text { where administrator at the collaborative portal can supply } \\
\text { those information though the portal's database. Students are } \\
\text { able to search for information on scholarship and demanded } \\
\text { fields of study etc., and portal administrator is able to } \\
\text { check/observe the query from the students to enhance and } \\
\text { update the offerings available for them at the collaborative } \\
\text { portal. }\end{array}$ & $\begin{array}{l}\text { Collaborative } \\
\text { System } \\
\text { Administrator }\end{array}$ \\
\hline Guardian & $\begin{array}{l}\text { Guardian can receive available information on the industry } \\
\text { needs, and they are able to put some suggestions at the } \\
\text { collaborative information system portal. On the other hand, } \\
\text { the administrator at the collaborative portal can supply } \\
\text { those information though the portal's database that is } \\
\text { demanded by the guardians. And also admin could receive } \\
\text { and manage the suggestions posted by guardians. }\end{array}$ & $\begin{array}{l}\text { Collaborative } \\
\text { System } \\
\text { Administrator }\end{array}$ \\
\hline Employer & $\begin{array}{l}\text { Employer can receive existing information on the } \\
\text { availability of Human Resource (HR), so that they may } \\
\text { contact or offer them jobs. On the other hand, the } \\
\text { administrator at the collaborative portal can supply those } \\
\text { information though the portal's database that is demanded } \\
\text { by the employers. As employers search for information on } \\
\text { HR availability; therefore, the administrator at the } \\
\text { collaborative information portal checks/observes the query } \\
\text { from the employers to further add, enhance and update the } \\
\text { offerings available for them at the collaborative portal. }\end{array}$ & $\begin{array}{l}\text { Collaborative } \\
\text { System } \\
\text { Administrator }\end{array}$ \\
\hline Policymaker & $\begin{array}{l}\text { Policymaker can receive particular existing information on } \\
\text { industry and academia from the collaborative portal where } \\
\text { the administrator can supply those information though the } \\
\text { portal's database that is demanded by the policymakers. } \\
\text { From the operation perspectives, policymaker clicks on } \\
\text { industry and academia section at the collaborative portal to } \\
\text { get information on industry needs, potential workforce } \\
\text { opportunities, education curriculum, academia needs. }\end{array}$ & $\begin{array}{l}\text { Collaborative } \\
\text { System } \\
\text { Administrator }\end{array}$ \\
\hline Educator & $\begin{array}{l}\text { Educator can receive existing information on industry and } \\
\text { academia, and the administrator at the collaborative } \\
\text { information portal can supply those information though the } \\
\text { portal's database that is demanded by the educators. } \\
\text { Educator clicks on industry and academia section at the } \\
\text { collaborative portal to get information on industry needs, } \\
\text { potential graduates' employability, and academic } \\
\text { curriculum. }\end{array}$ & $\begin{array}{l}\text { Collaborative } \\
\text { System } \\
\text { Administrator }\end{array}$ \\
\hline
\end{tabular}




\section{General Discussions and Implications}

The proposed model presents a significant concept of Collaborating Information Systems (CIS) that to be implemented among the four QHM actors in a country: Government, University, Industry and Citizen. Even though, the study focused in Malaysia context, but any other country can implement the similar concept in order to achieve high availability of information rich. The general users of this system would easily obtain necessary information especially education and job related information updates.

This study is just a conceptualization of the project. Based on the existing literature on collaborative information systems, we found that Sohn et al. (2007) have conducted study on the designing and implementing Information System for the MBO of National Research and Development Projects incorporated by Industries, Universities and Governmentsupported Research Institutions. That was a study on how to achieve successful implementation of massive research and development projects requiring collaboration among industries, universities and government-supported research institute. No other studies have been conducted on designing a collaborative information systems among the government, university and industry especially for current and potential graduates, parents, and as well as general public. Thus, future attempt of this study should take part into the implementation perspective where a structured description on the functionalities of each QHM/"WoG" actors (Government, University, Industry and Citizen) would be required.

\section{Conclusion}

This study proposes a collaborative information sharing system which would serve its users with wide and related information obtained from three key partners (government, university, and industry) in the context of Malaysia. It is expected that after successfully implementation of this system, the targeted users such as graduates, parents, government, employers, as well as all citizens would get the required information to make decision for their particulars. Graduates would know which sector has the high demand, parents would know which department the children need to be enrolled in, potential employers (government and industry) would know what the university is producing, and university would know what the skills industry demand for etc. Overall, this system would be a virtual platform for providing information on human capital development for strategic use of the country, particularly in Malaysia. There is an advantage for this system to be implemented or enhanced, is that for the three collaborative partners, each of them has an existing representative (Malaysia egovernment site, SME corporation site, and MQA web portal). Now the only effort needs is to initiate the collaboration.

\section{References}

'Innovation Xchange: Connecting for Collaborative Innovation,' [Retrieved April 20, 2012], http://ixc.com.my/

'Malaysian Qualification Agency: MQA at a Glance,' Internet: [Retrieved January 5, 2012],

http://www.mqa.gov.my/en/profil_sepinta s.cfm

Bénaben, F., Touzi, J., Rajsiri, V. \& Pingaud, H. (n.d). "Collaborative Information System Design,"

http://subs.emis.de/LNI/Proceedings/Pro ceedings92/gi-proc-092-018.pdf

Bothos, E., Apostolou, D. \& Mentzas, G. (2008). "A Collaborative Information Aggregation System for Idea Management," The Third International Conference on Internet and Web Applications and Services.

Collaboration. [Retrieved April 20, 2012], http://en.wikipedia.org/wiki/Collaboratio $\mathrm{n}$,

Denning, P. J. \& Yaholkovsky, P. (2008). "Getting to We," Communications of the ACM. pp.19-24. 
El-Bibany, H., Katz, G. \& Vij, S. (1991). 'Collaborative Information Systems: A Comparison of the Electronic and Facility Design Industries,' Center for Integrated Facility Engineering, Stanford University.

Farley, J. (1998). Distributed computing: Collaborative Systems. [Retrieved April 15, 2012], http://docstore.mik.ua/orelly/javaent/dist/ch09_01.htm

Getz, C. W. (1977). "Coalescence: The Inevitable Fate of Data Processing," Mis Quarterly. 1977, pp. 21-30.

Javanmardi, S. \& Lopes, C. V. (2007). "Modeling Trust in Collaborative Information Systems," International Conference on Collaborative Computing: Networking, Applications and Worksharing.

Kaur, R. (2006). "Malaysian e-Government Implementation Framework," [Retrieved April 15, 2012], http://dspace.fsktm.um.edu.my/bitstream /1812/79/1/Roslind\%20Kaur.pdf

Malaysia Government's Official Portal. [Retrieved April 21, 2012], http://www.malaysia.gov.my/EN/Pages/d efault.aspx

Malaysia University Portal. [Retrieved January 28, 2012], http://www.malaysiauniversity.net/aboutus/

MAMPU (2011). "The Malaysian Public Sector ICT Strategic Plan 2011-2015: Powering Public Sector Digital Transformation," [Retrieved October 10, 2011], http://www.mampu.gov.my

Molhort, P. (1985). "On Converging Paths: The Computing Center and the Library," Journal of Academic Librarianship.

Morris, M. R. (2008). "A Survey of Collaborative Web Search Practices," Proceedings of ACM SIGCHI. pp.1657-1660. MOSTI (2011). "Innovating Malaysia: National Innovation Policy," [Accessed April 25, 2012], http://www.innovation.my
Shah, C. (2008). Toward Collaborative Information Seeking (CIS). Proceedings of JCDL 2008 Workshop on Collaborative Exploratory Search.

Sohn, K.- J., Yoo, W.- J. \& Lee, C.- G. (2007). The Design and Implementation of Information System for the MBO of National R\&D Projects Cooperated by Industries, Universities and Governmentsupported Research Institutes. PICMET 2007 Proceedings.

SME Annual report (2009/10). Transforming to the New Economic Model. [Retrieved February 27, 2012], http://smeinfo.com.my/images/pdf/pandu an/appendix.pdf.

SME Business Directory. [Retrieved January 26, 2012]. http://smeinfo.com.my/index.php?option= com_wrapper\&view=wrapper\&Itemid $=126$ 4\&lang=en

SME Corporation Malaysia: List of Companies. [Retrieved April 25, 2012]. http://www.smecorp.gov.my/node/19

Swanson, E. B. \& Culnan, M. J. (1978). "Document-Based Systems for Management Planning and Control: A Classification, Survey and Assessment," Mis Quartely. Pp 31-46.

Twidale, M. B. \& Nichols, D. M. (1996). "Collaborative Browsing and Visualisation of the Search Process," Proceedings of Aslib. pp. 177-182.

Xiu, X. (2010). "Study of Collaborative Information Systems of 4PL Based on Internet," Second International Conference on Modeling, Simulation and Visualization Methods. 